\title{
Análisis de la propiedad industrial en Colombia : un análisis de la decisión andina 486 del año 2000
}

\author{
Analysis of industrial property in Colombia: an analysis of Andean decision 486 of \\ the year 2000
}

Lainiver Mendoza Munar PhD

Facultad de Derecho de la Universidad Cooperativa de Colombia Sede Cali, investigadora principa. El presente artículo surge como producto de la investigación denominada "Estudio comparado en propiedad intelectual para empresas desarrolladoras de software en la Comunidad Andina" de la Facultad de Derecho de la Universidad Cooperativa de Colombia Sede Cali. auxiliar de investigación Juan Fernando Villegas Motoa estudiante de X semestres del programa de Derecho I

Fecha de recepción: Septiembre de 2019

Fecha de aprobación: marzo de 2020

Para citar este artículo / To reference this article Análisis de la propiedad industrial en Colombia: un análisis de la decisión andina 486 del año 2000. Inciso, 22(1) ;

102-114.

DOl: http://dx.doi.org/10.18634/incj.22v.1i.996

\section{Resumen}

La Comunidad Andina -CAN- a través del Régimen Común Andino de Propiedad Industrial, aprobado por medio de la Decisión 486 de la Comunidad Andina, estipula acuerdos sobre Aspectos de los Derechos de Propiedad Intelectual Relacionados con el Comercio (ADPIC) aprobado en el marco de la Ronda Uruguay de la Organización Mundial del Comercio (OMC). Dentro de este tema se analizará la supranacionalidad y la aplicación de las normas en el orden local en materia de propiedad industrial, analizando su evolución frente a la reglamentación comunitaria, identificando principios comunes y como estos pueden afectar las relaciones transnacionales de los países miembros de la CAN.

Palabras clave: propiedad Industrial, derecho marcario, Innovación, comunidad Andina, signos distintivos. 


\section{Abstract}

The Andean Community -CAN- through the Andean Common Industrial Property Regime, approved through Decision 486 of the Andean Community, stipulates agreements on Aspects of Trade-Related Intellectual Property Rights (TRIPS) approved within the framework of the Uruguay Round of the World Trade Organization (WTO).

Within this topic, the supranational nature and application of the rules in the local order in the field of industrial property will be analyzed, analyzing their evolution in the face of community regulations, identifying common principles and how these can affect the transnational relations of the member countries of the DOG.

Keywords: industrial property, trademark law, innovation, andean community, distinctive signs.

\section{Introducción}

El presente documento tiene como objeto analizar la legislación de propiedad intelectual en los países de la Comunidad Andina de Naciones -CAN- en este caso son: Bolivia, Colombia, Ecuador y Perú y los principales procesos de armonización frente a la reglamentación local, con enfoque en propiedad industrial y dentro de este campo, se estudiaran aspectos de derecho marcario y especialmente se realiza énfasis en la regulación legislativa y la valoración dada por la Comunidad Andina frente al reconocimiento marcario dentro del ámbito de propiedad industrial. El presente análisis se enfoca en el estudio de la evolución de la Decisión 486 de la CAN, la metodología a utilizar será de tipo jurídica, la cual busca revisar la normatividad existente en la materia, la forma cómo operan las instituciones estatales y cómo estas ofrecen protección a las creaciones de carácter industrial, por otro lado, el método será comparativo por cuanto se buscará describir las similitudes y diferencias entre diversas variables sobre la propiedad intelectual en la CAN, dentro de las cuales se destacan: Principios legales, normas sustanciales y procesales.

En este sentido se pretende demostrar como la Decisión 486 ha sido una herramienta jurídica importante para la propiedad intelectual en Colombia y que sus aportes en materia de principialistica jurídica, han sido de gran valor para los miembros de la CAN.

\section{Desarrollo legislativo en materia de propiedad industrial en las decisiones de la Comunidad Andina}

Actualmente las creaciones intelectuales cuentan con un alto valor dentro de la dinámica empresarial y el desarrollo de los países, pues el conocimiento es considerado un activo muy valioso, por ende, merece especial atención y protección, por ello la propiedad intelectual se ha posicionado como uno de los recursos más significativos e importantes en el desarrollo de los países y su riquezas interna, conforme con lo anterior la dinámica empresarial tanto en el orden nacional como en el internacional se han preocupado por el creciente aumento de nuevos conocimientos y los diferentes Estados han creado regulaciones especiales, las cuales buscan otorgar protección y seguridad tanto a la obra como al autor de ella, dichas normas regulan la propiedad intelectual en sus dos dimensiones: derechos de autor y propiedad industrial; los derechos de autor se refieren a la manifestación del intelecto humano, el cual será plasmado ya sea en arte, obras literarias, soporte lógico o software, entre otros; la segunda regula las creaciones que cuentan con aplicación especial en el ámbito de la industria y el intercambio comercial, esta última incluye la creación de productos de industria y comercio o sus modificaciones, signos distintivos y nuevas creaciones, invenciones y/o descubrimientos industriales. 
Los derechos de autor versan sobre el espíritu mismo de la obra y se proyectan como la comunicación de ideas, mientras que los industriales atienden la producción del intelecto con el objeto de materializarlos de manera concreta en la transformación de materias primas (Becerra Puerto, 2010), sin embargo, tanto derechos de autor como propiedad industrial son considerados propiedad intelectual.

De esta manera, y de forma general, se denomina la propiedad intelectual, la cual no solo abarca el talento humano, sino también la capacidad de transformación de la materia, de tal forma que los derechos intelectuales se dividen en dos grandes campos: derechos de autor y propiedad industrial.

Los derechos de autor como lo expresa la Decisión 351 de la Comunidad Andina -CAN-, estipula la protección especial de los derechos de autor y derechos conexos, en la primera encontramos la:

Protección a los autores y demás titulares de derechos, sobre las obras del ingenio, en el campo literario, artístico o científico, cualquiera que sea el género o forma de expresión y sin importar el mérito literario o artístico ni su destino.

Mientras que la Decisión 486 de la CAN, establece la protección para las obras de carácter industrial en su artículo 2, determina:

Con respecto a la protección de la propiedad industrial, toda ventaja, favor, privilegio o inmunidad que conceda un País Miembro a los nacionales de otro País Miembro de la Comunidad Andina, se hará extensiva a los nacionales de cualquier miembro de la Organización Mundial del Comercio o del Convenio de París para la Protección de la Propiedad Industrial.

Con el fin de otorgar mayor claridad ambas decisiones, se establecen linderos de protección transnacionales, los cuales conceden el aprovechamiento económico de la obra como la participación en los beneficios de estas, es decir que, a pesar de los años, al autor siempre se le otorgará un reconocimiento no solo intelectual, sino también patrimonial incluso después de su deceso.

El significado de la propiedad industrial se percibe como la actividad creadora del ser humano, particularmente se usa para clasificar una serie de derechos sobre bienes inmateriales que se relacionan con la protección legal de la obra, su producto y proceso, el cual tiene aplicación industrial o comercial y ha sido creado por una persona o por una empresa (Suárez Pedreros , 2017)

La propiedad industrial se tiene como un derecho propio del creador, y se ve distribuido de la siguiente manera, una parte del derecho es adquirido por el creador de la invención y la otra parte por el productor o comerciante, el cual hace uso de signos distintivos para diferenciar su trabajo y resultado de otros.

De esta manera, se encuentran ciertas características que constituyen la propiedad industrial:

En primer lugar, la propiedad industrial es la única que regula las creaciones e invenciones del ser humano con aplicación industrial, es decir, para su registro se debe demostrar la utilidad de la creación, y su propiedad solo se acredita mediante acto administrativo siendo emitido por la autoridad competente para el caso colombiano.

En derechos de autor no es necesario demostrar la utilidad industrial o empresarial de una obra, tal es el caso de una obra de arte, la protección sobre este tipo de obras es automático, es decir, no requiere el reconocimiento de propiedad por parte de autoridad competente, su registro es opcional y será útil para fines probatorios o para hacerse oponible ante terceros. por este hecho, las normas contienen situaciones peculiares las cuales no se encuentran en otros sistemas normativos de tipo propietario, ello por cuanto aquí, se busca proteger las creaciones únicas con miras a la protección del interés público. 
En segundo lugar, se constituyen instituciones especiales las cuales se centran en la actividad y estudio de quien inventa el artefacto, ello, con el propósito de recolectar datos jurídicos, científicos y económicos con el objetivo de adoptar normativas especiales, con el fin de regular, proteger e integrar los nuevos conocimientos a los diversos sistemas actuales.

En tercer lugar, el factor inmaterial el cual se ve reflejado en la idea referida o artefacto creado como resultado final, en este factor, no se enfoca como tal en la cosa, si no en la idea que permite observar la explotación, utilidad y uso de la cosa.

En cuarto lugar, nos referimos a la regulación o evolución que se da a medida que avanza la industria y con ello las leyes que fundamentan la materia, debido a las nuevas formas de aplicación que trae consigo la implementación de nuevas tecnologías sean estas en el área científica, cultural u otra, esto con el fin de armonizar y vincularse de manera dinámica a los diferentes espectros de la propiedad industrial.

Finalmente, como quinto elemento, se destaca el carácter económico, el cual es por obvias razones el motor de progreso de nuevas innovaciones tecnológicas, este elemento es esencial para el desarrollo de las naciones, ello debido a que se constituye la propiedad industrial como un factor importante en el área de crecimiento de los Estados.

Ahora bien, para abarcar de manera integral este estudio es importante resaltar las diferentes divisiones que tiene la propiedad industrial sin ahondar en gran media en ellas, por cuanto, se pretende identificar la manera de protección otorgada por la decisión 486 de la Comunidad Andina frente al registro de la marca en los países miembros: La Propiedad Industrial representa para el empresario un conjunto de derechos que, siendo intangibles, constituyen en su gran mayoría, el más valioso de los activos con el que puede contar. (Meza Aguirre, 2013, pág. 31).

La propiedad industrial está conformada por dos grandes vertientes:

Las nuevas creaciones: son aquellas compuestas por las patentes de invención, modelos de utilidad, dibujos, diseños y secretos industriales.

Los signos distintivos: estos incluyen las marcas comerciales, lemas comerciales, nombres comerciales, enseñas comerciales y denominaciones de origen.

\section{Caso Colombia}

Con la apertura económica de Colombia se logró el fortalecimiento económico de bienes intangibles producto del intelecto humano. Este tipo de temáticas ha sido objeto de debate político y científico, es por ello, que se ha incluido el desarrollo de nuevas tecnologías en los planes de desarrollo POT de las últimas legislaturas.

La Constitución Política de Colombia del año 1991. En Colombia la función de legislar en materia de propiedad industrial fue es trasladada a la Comunidad Andina, la cual regula específicamente a través de la Decisión 486 todo lo referente a la propiedad industrial, la función del Congreso de la República es dictaminar pautas de procedimiento en pro de otorgar protección adicional a la ya concebida.

Si bien la propiedad industrial está establecida como una de las vertientes principales de desempeño y desarrollo económico de la Nación, en nuestro país este tema hasta ahora empieza a cobrar importancia debido a la globalización y comercio dado en la última década. 
Para analizar el impacto y desarrollo de la propiedad industrial dentro de la economía colombiana es importante estudiar a las patentes, debido a que estas tienen un mayor ámbito de aplicación práctica. Cuando hablamos de patentes en Colombia en realidad es importante aclarar que en gran parte las patentes, pertenecen a compañías extranjeras, puesto que estas son dueñas del (90\%) de las patentes otorgadas.

Los países desarrollados son considerados como los mayores importadores de innovación patentada, sin embargo, países como Colombia, Chile, Bolivia, Perú, entre otros, se encuentran en vía de desarrollo y son considerados como los mayores desarrolladores de innovación, no en cuanto a la invención de algo como tal, sino a la mejora y desarrollo de nuevos métodos frente a lo ya preexistente. (Revista Editorial Dinero, 2017).

Un estudio realizado por el (Departamento Nacional de Planeación, 2018) Indica que el treinta y siete por ciento (37\%) de las patentes concedidas en Colombia, son propiedad de diez compañías extranjeras, las cuales son propietarias de entre 20 y 300 patentes cada una. Menciona (Sánchez Blanco, 2006, pág. 25) Que sí bien la concentración de patentes está dada en el extranjero, el factor interesante, radica en que estas compañías invierten en Latinoamérica, debido a que existe un sistema sólido de protección para sus productos, adicional a ello, se permite en Colombia acceder a tecnologías importantes con fines de desarrollo. Sin embargo, es necesario aceptar y admitir que las patentes otorgadas en Colombia en su gran mayoría no son explotadas en el territorio, ello conforme a cifras dadas por la Superintendencia de Industria y Comercio entre los años 2000 hasta el año en curso se han otorgado un poco más de dos millones de patentes de las cuales el $11.51 \%$ pertenecen a residentes nacionales y el $88.49 \%$ a no residentes.

Graficas de desarrollo histórico de producción de propiedad intelectual en Colombia
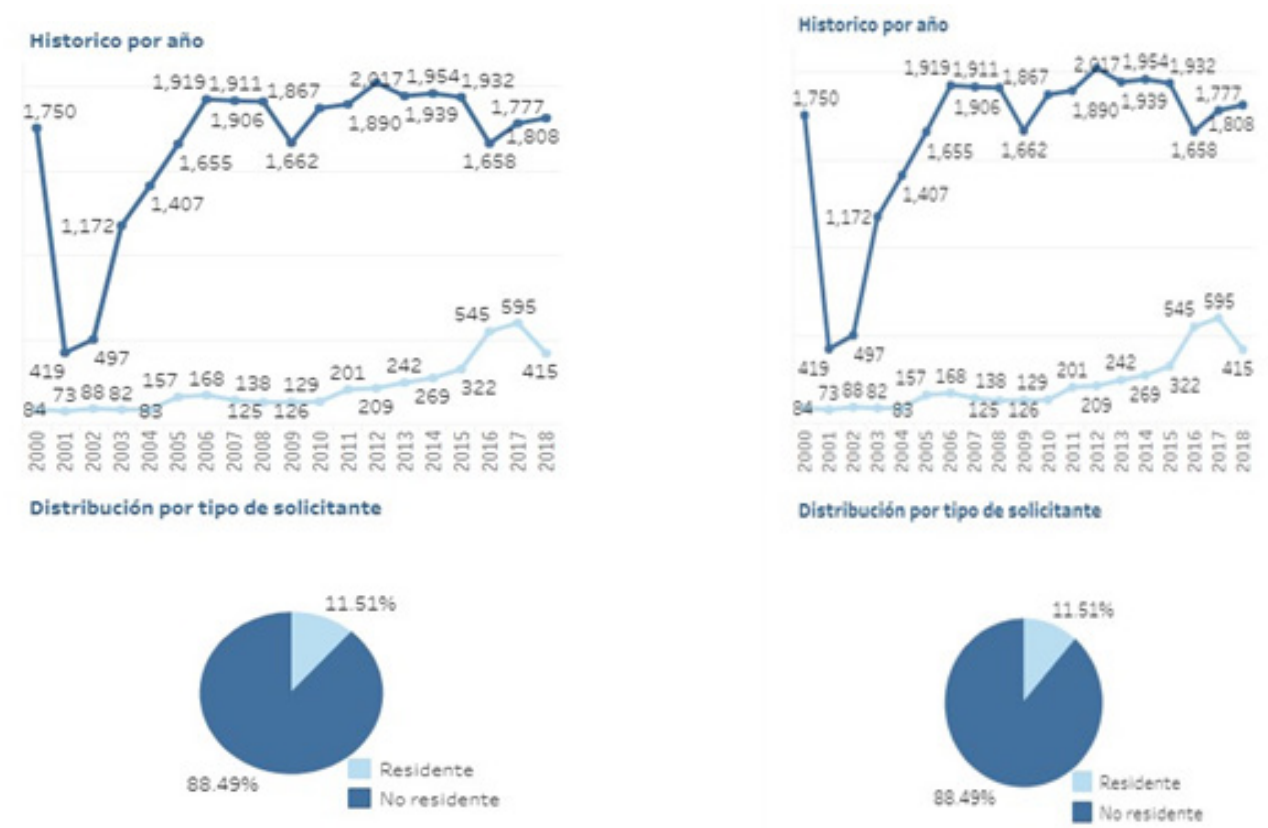

Obtenido de: (Centro de Informacion Tecnologica y Apoyo a la Gestion de la Propiedad Industrial, 2019) 
Lo anterior indica que, sí bien es cierto, el sistema de protección de derechos de propiedad en Colombia no ha sido un medio muy eficaz para conseguir innovación y riqueza como se pretende, sí se configura este como una herramienta útil para conseguir ese propósito siempre y cuando se constituya como un sistema eficaz y en constante actualización de conformidad con las tendencias mundiales, las cuales generan mayor participación y competencia en la creación de nuevas tecnologías. (Centro de Informacion Tecnologica y Apoyo a la Gestion de la Propiedad Industrial, 2019)

En Colombia es claro que existe innovación, sin embargo, el problema radica en la carencia de recursos económicos necesarios para la explotación de las obras. Por ello, no se puede medir la capacidad de innovación de acuerdo con la cantidad de solicitudes de patentes que se presentan, sino por su capacidad de explotación. En Colombia, patentar representa un alto costo el cual, en ocasiones, no es factible de ser adquirido, es por ello, que aún se evidencia la cultura de la no patentabilidad.

\section{Procesos de armonización del derecho de la propiedad industrial en los países de la Comunidad Andina}

Continuando con el desarrollo de este análisis, haremos una breve reseña de los antecedentes que dieron origen a la Decisión 486 de la Comunidad Andina, la cual, incluye: el Convenio de París que fue la primera normativa internacional con respecto a la protección de invenciones, seguidamente hablaremos de algunas de las Decisiones y convenios que antecede con respecto a la protección de derechos de propiedad Intelectual que envuelven a la propiedad industrial relacionados con el comercio los cuales dieron como resultado final la Decisión 486 de la Comunidad Andina.

\section{Convenio de París}

Este convenio constituye el marco jurídico de la propiedad industrial, firmado por once Estados en 1883 durante la conferencia diplomática de París, con el nombre de "Convenio de París para la Propiedad Industrial" contiene disposiciones de carácter administrativo con respecto al funcionamiento y estructura del ente jurídico encargado de la protección de los derechos de propiedad industrial, se divide en dos ámbitos: el primera contiene disposiciones generales aplicables a todos los derechos de propiedad Industrial tales como (el principio de trato nacional, el derecho de prioridad y la asimilación a la condición de nacionales), por otro lado, la segunda parte hace referencia a temas específicos como patentes, marcas, nombres comerciales, diseños industriales y medidas contra la producción ilícita. (Convenio de Paris, 1883)

\section{Acuerdo de Cartagena}

El acuerdo de Integración Subregional Pacto Andino, denominado como Acuerdo de Cartagena fue creado en Bogotá el 26 de mayo de 1969 entre Bolivia, Colombia, Chile, Ecuador y Perú, este tenía como propósito agrupar las economías latinoamericanas con el fin de tener una herramienta para negociar las condiciones semejantes entre firmantes, para así, contar con desarrollo equitativo entre los miembros, logrando integración económica de naciones, este Acuerdo fue aprobado mediante el decreto 1245 de 1969 y con su creación surge para la Comunidad Andina la facultad de poder regular como ente supremo sobre ciertos aspectos referentes a la Propiedad Industrial, ello fundado en la Supranacionalidad surgida entre quienes aceptan la aplicación y competencias de este órgano con respecto a determinadas decisiones (Parlamento Andino, 2018).

El artículo 27 de este acuerdo establece la obligación de las naciones en adoptar un (régimen común sobre el tratamiento de marcas, patentes, licencias y regalías). conforme a ello se aprobó la Decisión 24 que establece el régimen común sobre capitales extranjeros. Este regula aspectos fundamentales 
relativos a la adquisición y negociación de nuevas tecnologías, de igual forma, incluye aspectos relativos a contratación, licencias de uso de patentes y marcas de origen extranjero.

La Decisión 85 regula la aplicación de normas sobre propiedad industrial. En Colombia la Decisión 85 fue integrada mediante el decreto 1190 de 1978. Esta decisión tiene como propósito unificar las legislaciones de los diferentes países miembros a fin de otorgar una mejor protección a las obras, sin embargo, todo lo que no esté estipulado en esta, estará sujeto a la legislación interna de cada uno, es por ello, que los firmantes deben adaptar su ley interna a fin de regular aspectos fundamentales que no se encuentren dispuestos en la Decisión 85. (World Intellectual Property Organization , 1974).

La Decisión 311 reemplazó a la Decisión 85 e introdujo reformas y adiciona otras enmiendas relativas a la propiedad industrial y su régimen dentro de la comunidad andina, sin embargo, ello no fue suficiente, por tanto se creó la Decisión 344, la cual fue expedida el 29 de octubre de 1993, cuya reglamentación en Colombia se dio mediante el Acuerdo de Cartagena que fue aprobado el 26 de mayo de 1969 por los plenipotenciarios de los países signatarios, siendo después incorporado al ordenamiento jurídico colombiano por el Decreto 1245 de 1969 y posteriormente por la Ley $8^{a}$ de 1973. con esta nueva decisión se pretendía perfeccionar y corregir las anteriores decisiones, otorgando un amplio campo de aplicación en materia de patentabilidad, licencias y otorgamiento de patentes, pero a pesar de ello, no constituyó un cambio en el ámbito de aplicación normativa (Legal Legis, 1991). porque sí bien, este contaba con ocho (8) capítulos en los que trataba (patentes, modelos de utilidad, diseños industriales, secretos industriales, marcas, nombre comercial, denominaciones de origen y disposiciones complementarias) siguieron existiendo falencias las cuales fueron tratadas en su totalidad por la Decisión 486 que se encuentra actualmente vigente y con la que se pretende adaptar las normas de Propiedad Industrial a nivel Supranacional a fin de lograr una verdadera protección Industrial a nivel internacional (Moure, 2001, pág. 40)

\section{El Acuerdo sobre los aspectos de los derechos de propiedad intelectual relacionados con el comercio (ADPIC)}

Se creo para beneficiar tanto a los países industrializados, como a los que están en vía de desarrollo (Organizacion Mundial del Comercio, 1994)

Este acuerdo se constituye como el punto inicial de este análisis, puesto que modifica la Decisión 344 de la normatividad Andina, donde Colombia durante la ronda Uruguay fue uno de los países que asumió cumplir con las obligaciones establecidas en el acuerdo, a continuación una breve reseña sobre los aspectos más relevantes del Acuerdo sobre Derechos de Propiedad Intelectual relacionados con el comercio y aranceles aduaneros, firmado el 30 de Octubre de 1947 por 23 países promotores de la Carta de la Organización Internacional del Comercio o lo que hoy se conoce como OMC.

EI GATT (Acuerdo General sobre Aranceles Aduaneros y Comercio) fue concebido como un compromiso institucional, el cual establece disposiciones técnicas que regulan el comercio internacional de bienes y productos (Organización Mundial del Comercio, 1947).

(Organización Mundial del Comercio, 1947) El GATT se basa en dos principios fundamentales: El primero no, discriminación, es decir, no se observa la calidad de las partes contratantes. Este principio se crea a partir del establecido en el artículo primero del GATT Sobre "La Nación más favorecida" El cual estipula lo siguiente:

Cualquier ventaja, favor, privilegio o inmunidad concedido por una parte contratante a un producto originario de otro país o destinado a él, será concedido inmediata e incondicionalmente a todo producto similar 
originario de los territorios de todas las demás partes contratantes o a ellos destinado. (World Intellectual Property Organization, 2000, pág. 507)

De igual forma, en segundo lugar en el artículo tercero del acuerdo, estipula que los productos provenientes de otros países no tendrían un trato menos favorable. El articulo reza:

Los productos del territorio de toda parte contratante importados en el territorio de cualquier otra parte contratante no deberán recibir un trato menos favorable que el concedido a los productos similares de origen nacional (Organización Mundial del Comercio, 1947, pág. 507).

Con base en lo anterior, se constituyeron los pilares base de la Propiedad Industrial en el sistema GATT y se garantizó su aplicación y eficacia normativa dentro de un contexto de "Protección". Este, comprendió normas relativas a la existencia, mantenimiento, observancia, alcance y ejercicio de los derechos. A raíz de ello, se logró generar ventajas legislativas a nivel nacional, las cuales regularon y otorgaron mayor protección, Sin embargo, al momento de adquirir y mantener los derechos establecidos en los acuerdos internacionales celebrados dentro de la OMPI, no siempre se tienen en cuanta dichos principios antes mencionados, ello, debido a cuestiones políticas o económicas. Un claro ejemplo de ello es el artículo cuarto.

La función principal del GATT consiste en establecer normas para regular el comercio internacional con el fin de suprimir barreras comerciales y solucionar los conflictos internacionales. Se trata de un catálogo de normas apoyado en una estructura estable, y a la vez se constituye como un foro de discusión multilateral de los problemas comerciales que pretende impulsar el crecimiento económico, el desarrollo de comercio internacional de productos, y como órgano para la conciliación y solución de las controversias entre las partes. Mundialmente se reconoce la incidencia del GATT sobre el crecimiento del comercio internacional. (Universidad Javeriana de Colombia, pág. 78).

Con los convenios llevados a cabo en 1947 durante la ronda de Uruguay los países miembros del GATT se comprometieron a establecer ventajas reciprocas a diferentes niveles económicos como: "La reducción de aranceles y el levantamiento de barreras comerciales que involucraran discriminación internacional". Desde sus inicios el GATT ha llevado a cabo diferentes rondas, la cuales se han centrado en la necesidad de librar el comercio exterior de barreras tanto a nivel de arancel como también legislativo, con la finalidad de mejorar el acceso a la protección y comercio globalizado.

Finalmente se debe resaltar que la GATT tiene un concepto amplio con respecto a propiedad intelectual dentro de los países desarrollados, los cuales, han adoptado los acuerdos en prácticamente todas sus modalidades Asimismo, se han implementado normas relativas al procedimiento de reconocimiento y protección de los derechos de propiedad intelectual, entre estos se comprenden medidas como: la protección de frontera y mecanismos de consulta y solución de conflictos entre las partes. En la medida en que los países en desarrollo adquieran una visión amplia de los derechos de propiedad intelectual relacionados con el comercio, se iniciara la implementación y fortalecimiento de los derechos en el marco del GATT.

Con la llegada del Régimen Común sobre Propiedad Industrial Decisión 486 se buscó adecuar la norma comunitaria a los estándares y obligaciones internacionales, concretamente hablando en propiedad intelectual enfocada en las relaciones de comercio desde su entrada en vigor en el año 2000.

Esta nueva decisión no representa un gran cambio frente a su parte sustancial y derechos de propiedad industrial, no obstante, se llevó a cabo un análisis extenso durante alrededor 3 años para la expedición de esta nueva decisión que trae consigo (133) nuevos artículos para un total de (280) en comparación con la 
anterior de (147) articulo; En estos, se logró reflejar y evitar la discrepancia y se buscó la armonización de la norma evitando la duplicidad en interpretaciones y unificación de procedimientos.

Ahora bien, la decisión incorporó aspectos vanguardistas, entre ellos el principio de la nación más favorecida, igualmente, temas referentes a recursos biológicos y genéticos, los cuales son hito de discusión tanto a nivel nacional e internacional. Por otro lado, se adecuaron temas procedimentales y se otorgó mayor claridad con respecto a lo estipulado en la Decisión 391 que estipula el Régimen Común sobre acceso a los recursos genéticos.

De manera sucinta se analizó los cambios que trae consigo la Decisión 486 frente a la 344, con base a aspectos relevantes y las principales razones de cambio de la nueva decisión con respecto de la anterior, con el objetivo de generar una herramienta de consulta para aquellos estudiosos de la Propiedad Industrial. (Universidad Javeriana de Colombia, pág. 105)

Primeramente, hablaremos del principio de la nación más favorecida, este nuevo aparte sigue la tendencia mundial de no reconocer ventajas económicas sobre los países aliados, salvo algunas excepciones, con ello, se buscó remover y evitar los obstáculos al comercio mundial y generar un trato igualitario entre naciones con el fin de que ningún país pueda reconocer derechos inferiores a los que ya están establecidos. Ejemplo de ello: la reducción del tipo arancelario aplicable a uno de sus productos) (World Intellectual Property Organization, 2000, pág. 1)

Los principios de Trato nacional y nación más favorecida se encuentran regulados en el GATT y en la OMC, estos permiten establecer excepciones, como que los países que forman parte de un acuerdo subregional o regional pueden establecer acuerdos de libre comercio que establezcan la no aplicación de estos principios para las importaciones provenientes de países terceros.

Por otro lado, el Acuerdo de Cartagena es un pacto subregional que incluye expresamente la regulación referente al contenido y el alcance de los acuerdos internacionales, los cuales no pueden ser modificados por los países miembros a menos que se realice una reforma al acuerdo mismo.

Ahora bien, la Decisión 486 amplió la protección con respecto de la propiedad industrial significativamente, añadiendo temáticas como el patrimonio biológico y genético y conocimientos tradicionales. Este fue un aporte realmente significativo, ya que Colombia y los países miembros de la Comunidad Andina no cuentan con una riqueza amplia en materia de biodiversidad, es por ello que merece especial atención y protección; en los países andinos existen comunidades indígenas, afroamericanas y locales, quienes cumplen un papel muy importante en la conservación y preservación de los recursos de la biodiversidad, por ser poseedores de conocimientos autóctonos que componen material intangible asociado a los recursos genéticos y biológicos.

Es importante señalar que la biotecnología ha revolucionado la vida del ser humano debido a sus logros en el campo de la salud, la alimentación y el medio ambiente. Es por ello, que las patentes sobre invenciones biotecnológicas precisan de una adecuada protección jurídica según los compromisos contraídos en el ADPIC, son un instrumento para el desarrollo de nuevas tecnologías que pueden ser ampliamente aprovechadas por el ser humano. (Universidad Javeriana de Colombia, pág. 116)

Cabe aclarar que la objeción ética generalizada que existe en contra de las patentes de biotecnología en general o en contra de una categoría entera de las mismas, por ejemplo, "aquellas que utilizan material biológico humano, resulta imprecisa e inadecuada" (Universidad Javeriana de Colombia, pág. 116) 
Se debe tener en cuenta que la patente únicamente se otorga previa evaluación objetiva y valoración ética de la invención, bajo las causales expresas de exclusión establecidas en la legislación. Por consiguiente, estas invenciones nunca quedan eximidas del juicio ético; este se hace siempre de acuerdo con el uso normal e intencionado del invento, de manera previa y específica para cada caso. (Universidad Javeriana de Colombia, pág. 109)

En la Decisión 486 las patentes de invención constituyen un elemento vanguardista en el desarrollo legislativo nacional e internacional, sin embargo, se tiene un pensamiento inequívoco sobre aquellas que tornan sobre productos provenientes de la naturaleza, puesto que se cree que un producto natural instaura derechos sobre la naturaleza. La patentabilidad de una invención biotecnológica tiene como punto de partida la confrontación de esta, con las condiciones generales de patentabilidad, es decir, es novedosa. Por otro lado, cabe tener en cuenta que aquello que es hallado en la naturaleza no es considerado como una invención, si no como un hallazgo no patentable.

Dicho lo anterior, para que un producto o proceso sea considerado como una invención patentable (biotecnológica), se debe determinar la intervención del ser humano en ella, a tal nivel que sea posible diferenciar su procedencia, es decir sí el resultado obtenido es diferente al de la naturaleza, puesto que esta no podría producir uno igual por sus propios medios.

El campo de la biología es basto y aún quedan compuestos asociados al entorno natural, lo cual imposibilita su uso directo en materia de investigación, el mérito será otorgado al primero que logre aislar la forma o compuesto que interese, identificarlo e indicar su aplicación industrial y ponerlo a disposición del público, lo cual era una posibilidad que no permitía la naturaleza. La intervención del hombre lo convierte en algo no encontrado en la naturaleza, por consiguiente, patentable. De esta forma se han introducido al mercado sustancias de enorme valor terapéutico en beneficio del hombre. (National Human Genome Research Institute)

En el campo agroindustrial los genes han sido de gran ayuda, puesto que con estos se puede transferir y mejorar la capacidad de reproducción y desarrollo de sustancias de gran aporte nutricional y alimentario de la humanidad. Igualmente, con ello, se mejora la resistencia a plagas, lo que conlleva a un mejor uso de sustancias toxicas que ponen en riesgo la vida humana. La aplicación de biotecnología en cultivos cuenta con una amplia aplicación, por ello, Colombia adoptó el protocolo para biodiversidad "vegetales alterados deliberadamente por la introducción de material genético o la manipulación de su genoma". Mediante la Resolución 3492 de diciembre de 1998 del ICA (Instituto Colombiano Agropecuario) Por el cual se reglamenta y se establece el procedimiento para la introducción, producción, liberación, y comercialización de organismos modificados genéticamente (OMG) que fue derogada por la resolución 946 de 2006 artículo 46 del instituto colombiano agropecuario. (Instituto Colombiano Agropecuario ICA, 1998)

Finalmente, desde el punto de vista científico no es correcto distinguir los genes según su fuente, ello por cuanto, desde la propiedad industrial no es posible jurídicamente patentar aquellas invenciones provenientes de genes humanos dado que la vida humana no puede patentarse. El ADN no es vida, sino una sustancia química que lleva información útil que tiene gran significado en el desarrollo del ser humano, principalmente en el área médica. las patentes de invención que involucren sustancias que provengan del hombre, no confieren al propietario ningún derecho sobre otro ser humano. Ningún hombre es afectado de ninguna manera por la patente, ya que en la mayoría de los casos la sustancia humana es producida técnicamente mediante la utilización de organismos unicelulares, como bacterias, algas, hongos o protozoos. 
Conforme al análisis llevado a cabo, podemos concluir que el Régimen Común de Propiedad Industrial regulado en la Decisión 486 de la Comunidad Andina es uno de los regímenes más desarrollados de América Latina en cuanto a propiedad industrial se trata. Esta nueva regulación se constituye como una herramienta para el desarrollo tecnológico y científico con aplicativo industrial dentro de las naciones, de tal forma que inversionistas nacionales y extranjeros logran evidenciar con claridad el alcance y protección a los derechos de propiedad intelectual desarrollados en los países pertenecientes a las CAN, en los cuales se otorga mayor seguridad jurídica, generando así interés para participar activamente en el mercado, favoreciendo el desarrollo tecnológico, científico e industrial de los países aliados.

\section{Conclusiones}

Luego de un extenso análisis se logrado evidenciar de manera amplia y general como la Decisión 486 trae consigo cambios significativos con respecto al derecho procedimental de la propiedad industrial dentro de la Comunidad Andina (CAN), puesto que con esta se logró ampliar el campo de protección de manera extensa, se pasó de 147 artículos con la decisión 344 a 280 artículos con la decisión 486, ello da entender la preocupación e interés de los firmantes por otorgar protección y derechos a quienes son autores de nuevas creaciones provenientes del talento humano.

Por otro lado, se integraron aspectos novedosos como lo fueron: los principios de Trato nacional y Nación más favorecida, con los cuales se logró la reducción del tipo arancelario aplicable a productos provenientes de otras naciones, de igual manera, se reguló lo referente a recursos biológicos y genéticos, conforme a la decisión 392 y se adecuaron aspectos referentes a la propiedad intelectual relacionados con el comercio, entre otros. Sin embargo, uno de los aspectos más trabajados en la Decisión 486 fue el factor procedimental y la claridad de las normas incorporas, dejando de lado un poco el aspecto sustancial de la norma, es por ello, que se hace menester en hacer énfasis en cómo ello puede lograr a afectar las relaciones transnacionales referentes a la propiedad industrial de cada una de las naciones pertenecientes a las CAN.

Finalmente, cabe mencionar que la Decisión 486 de la Comunidad Andina nos plantea un gran reto, puesto que, nos lleva a discutir temas de propiedad intelectual, propiedad industrial, patentabilidad, protección, regulación de derechos intelectuales a nivel internacional y otros temas afines, de ahí que, se hace necesario buscar alternativas más allá del papel, las cuales, sean capaces de definir convenientemente la participación de los diferentes actores involucrados en la creación, desarrollo, innovación y protección de propiedad industrial otorgando el debido reconocimiento dentro de los países pertenecientes a la CAN sin desconocer los derechos sustanciales de quienes han elaborado el aplicativo industrial.

Es de gran importancia crear un marco normativo que permita en materia marcaría un registro comunitario, con esto se mejoran las ventajas competitivas de la región y se consolida la naturaleza integracionista de la CAN.

\section{Referencias bibliograficas}

Becerra Puerto, D. P. (28 de Noviembre de 2010). La globalización y el crecimiento empresarial a través de estrategias de internacionalización. Obtenido de Pensamiento \& Gerstion: http://rcientificas. uninorte.edu.co/index.php/pensamiento/article/view/1025/4971

Centro de Informacion Tecnologica y Apoyo a la Gestion de la Propiedad Industrial. (2019). SuperIntendecia de Industria y Comercio. Obtenido de Estadísticas Propiedad Intelectual: http://www.sic.gov.co/ estadisticas-propiedad-industrial. 
Cervera, R. C. (2014). Métodos y Técnicas de Investigación en Relaciones Internacionales Curso Doctoral. Obtenido de Universidad Complutense de Madrid: https://www.ucm.es/data/cont/media/www/ pag-55163/2Metodos.pdf

Cibepyme. (2013). (Cibepyme) Plataforma Iberoamericana de Propiedad Intelectual Dirigida a Empresas . Obtenido de Signos Distintivos: http://www.cibepyme.com/minisites/colombia/es/ propiedad-intelectual/propiedad-industrial/signos-distintivos/

Comunidad Andina. (02 de 07 de 1996). Decisión 391. Obtenido de World Intellectual Property Organization: https://www.wipo.int/edocs/lexdocs/laws/es/can/can011es.pdf

Comunidad Andina. (14 de Septiembre de 2000). World Intellectual Property Organization. Obtenido de DECISION 486: https://www.wipo.int/edocs/lexdocs/laws/es/can/can012es.pdf

Convenio de Paris. (20 de Marzo de 1883). OMPI. Obtenido de Convenio de París para la Proteccion de la Propiedad Industrial: https://www.wipo.int/treaties/es/text.jsp?file_id=288515

Departamento Nacional de Planeación. (2018). Pacto por Colombia por la Equidad. Obtenido de Bases del Plan Nacional de Desarrollo: https://colaboracion.dnp.gov.co/CDT/Prensa/PND-2018-2022.pdf

Giraldo, J. A. (2012). Metodologia y tecnica de la investigacion juridica. Bogota: Ediciones Uniandes.

Instituto Colombiano Agropecuario ICA. (22 de 12 de 1998). RESOLUCIÓN 3492 DE 1998. Obtenido de Legal Legis: http://legal.legis.com.co/document/Index?obra=legcol\&document=legcol_759920418cf1f034e0430a010151f034

Legal Legis. (8 de Noviembre de 1991). Legal Legis. Obtenido de DECISIÓN 311 DE 1991: http:// legal.legis.com.co/document/Index?obra=legcol\&document=legcol_759920413d4ff034e0430a010151f034

Meza Aguirre, M. (2013). Academia. Obtenido de Tratado de Derecho de la Propiedad Industrial: https:// www.academia.edu/7629847/151958087-Tratado-de-Derecho-de-La

Moure, J. G. (2001). Revista Universidad Externado. Obtenido de La Reforma de la decision 344 y su puesta en conformidad con las normas ADPIC: https://revistas.uexternado.edu.co/index.php/ contexto/article/download/1760/1568/

National Human Genome Research Institute. (s.f.). Genome.gov. Obtenido de La propiedad intelectual y la genomica: https://www.genome.gov/es/about-genomics/policy-issues/Intellectual-Property

Organización Mundial del Comercio. (30 de Octubre de 1947). Organización Mundial del Comercio. Obtenido de El GATT y el Consejo del Comercio de Mercancías: https://www.wto.org/spanish/ tratop_s/gatt_s/gatt_s.htm

Organización Mundial del Comercio. (1947). Organización Mundial del Comercio. Obtenido de Acuerdo General Sobre Aranceles Aduaneros y Comercio GATT: https://www.wto.org/spanish/docs_s/ legal_s/gatt47.pdf

Organizacion Mundial del Comercio. (15 de Abril de 1994). Organizacion Mundial del Comercio. Obtenido de Aspectos de los derechos de propiedad intelectual relacionados con el comercio: https://www. wto.org/spanish/docs_s/legal_s/27-trips_01_s.htm 
Organizacion Mundial del Comercio. (15 de Abril de 1994). Organizacion Mundial del Comercio. Obtenido de Aspectos de los derechos de propiedad intelectual relacionados con el comercio: https://www. wto.org/spanish/docs_s/legal_s/27-trips_01_s.htm

Parlamento Andino. (25 de Mayo de 2018). Parlamento Andino. Obtenido de Firma del Acuerdo de Cartagena: https://parlamentoandino.org/firma-del-acuerdo-de-cartagena/

Revista Editorial Dinero. (7 de Agosto de 2017). Dinero. Obtenido de ¿Cómo está Colombia en patentes en comparación con otros países?: https://www.dinero.com/emprendimiento/articulo/crecimiento-de-las-patentes-en-colombia-y-el-mundo/247386

Roman, L. L., Montenegro de Timaran , M. I., \& Tapia Fierro, R. M. (2006). La investigacion, eje fundamental de la enseñanza del derecho. Guia practica. Bogota: Editorial Universidad Cooperativa de Colombia. Obtenido de La investigacion, eje fundamental de la enseñanza del derecho. Guia practica: https://books.google.com.co/books?id=KpWmGvA3ASOC\&pg=PA39\&lpg=PA39\&d$q=\mathrm{La}+$ investigaci\%C3\%B3n+exploratoria+se+da+mediante+investigaciones+preliminares+que+establecen+un+contacto+m\%C3\%A1s+estrecho+con+el+objeto+de+que+se+desea+estudiar,+con+el+fin+de+efectua

Sánchez Blanco, M. C. (2006). Repositario Universidad de la Salle. Obtenido de La Investigación Cientifíca y el Desarrollo Tecnológico (Protegido a Través del Sistema de Patentes) y su Incidencia.: https:// ciencia.lasalle.edu.co/cgi/viewcontent.cgi?article=1399\&context=economia

Suárez Pedreros, H. N. (2017). Repositorio Universidad Catolica. Obtenido de UNIVERSIDAD CATÓLICA DE COLOMBIA: https://repository.ucatolica.edu.co/bitstream/10983/14297/1/ Art\%C3\%ADculo\%20de\%20investigaci\%C3\%B3n\%20propiedad\%20industrial\%20heidy\%20 pedreros.pdf

Universidad Javeriana de Colombia. (s.f.). Universidad Javeriana de Colombia. Obtenido de Decision 486 de la Comunidad Andina: Regimen Común sobre Propiedad Industrial: https://www.javeriana. edu.co/biblos/tesis/derecho/dere4/Tesis-45.pdf

World Intellectual Property Organization . (5 de Junio de 1974). WIPO. Obtenido de World Intellectual Property Organization (Desicion 85): https://www.wipo.int/edocs/lexdocs/laws/es/can/can018es.pdf

World Intellectual Property Organization. (14 de Diciembre de 1970). WIPO. Obtenido de World Intellectual Property Organization (Decision 486): https://www.wipo.int/edocs/lexdocs/laws/es/can/ can019es.pdf

World Intellectual Property Organization. (2000). WIPO. Obtenido de Regimen Comun de Propiedad Industrial: https://www.wipo.int/edocs/lexdocs/laws/es/can/can012es.pdf 